\title{
Gene expression analysis related to ethylene induced female flowers of cucumber (Cucumis sativus L.) at different photoperiod
}

\author{
Muhammad Maulana Malikul Ikram - Rizkita Rachmi Esyanti - Fenny Martha Dwivany
}

Received: 12 May 2017 / Revised: 27 July 2017 / Accepted: 22 August 2017

(c) Korean Society for Plant Biotechnology

\begin{abstract}
Photoperiod is one of the factors affecting productivity of cucumber plant by inducing ethylene hormone production and so triggering flower sex differentiation into female flower. However, only few studies have been perfomed in order to reveal the effect of photoperiod in molecular level in relation to the flower differentiation. Therefore, in this study, Mercy cultivar of cucumber (andromonoecious) was treated with photoperiod of $8,12,16$ hours of light, while control received no treatment of additional light. Photoperiod of 8 hours was achieved by blocking the sunlight with shade net and 16 hours by giving longer light exposure using white LEDs. Cucumber's flowers were quantified and the apical and lateral shoots were extracted to evaluate the gene profile related to the photoperiod, ethylene production, and female flower differentiation, which were CsACS2, CsETR1, CsCaN, and CsPIF4 using PCR method. Photoperiod of 8 hours affected the production of female flower with average number of 6.7 flowers in main stem and 8.0 flowers in lateral stem, compared to photoperiod of 12 and 16 hours which produced 3.7 and 2.0 flowers in main stem with 7.0 and 11.3 in lateral stem, respectively. In silico studies in this experiment resulted in proposed model of signal transduction that showed the connection between ethylene production and flower differentiation. PCR analysis confirmed the expression of CsACS2, CSETR1, and CsCaN, that was positively correlated with numbers of female flowers in cucumber, but the expression of CsPIF4 that represent photoperiod haven't been confirmed correlated with the ethylene production and flower differentiation.
\end{abstract}

Keywords CsACS2, CsCaN, CsETR, Cucumis sativus, Female flower, Photoperiod

M. M. M. Ikram • R. R. Esyanti $(\bowtie) \cdot$ F. M. Dwivany School of Life Science and Technology, Institut Teknologi Bandung, Bandung 40132, Indonesia

e-mail: rizkita@sith.itb.ac.id

\section{Introduction}

Production of cucumber (Cucumis sativus L) in 2015 was 447.677 ton/year in plantations covering 43.573 ha, so that it was one of the biggest horticultural plants in Indonesia (Indonesia Ministry of Agriculture, 2016). Other than commonly consumed as fruit-vegetable food, cucumber has been used traditionally to cure sore throat and fever. Furthermore, cucumber is also used as raw materials to produce facial cleansing agent in cosmetic industries, and contain cucurbitacin that is potential as a cure for cancer in pharmaceutical industries (Scout and Myers 2010; Lee et al. 2010; Chen et al. 2005).

Conventional cultivation of some cucumber cultivars resulted a very low productivity due to low numbers of female flowers produced in the early stage of flowering (Johnson 2008). One of the factors that affects flowering is photoperiod. Generally, cucumber is known as a neutral day plant, in which its flowering process is independent of daylength (Savonen 2003; Reece, et al. 2012). However, based on other study, andromonoecious, gynomonoecious, and hermaphrodite cultivar that were treated with low temperature and short-day condition promoted femaleness in cucumber plants, while high temperature condition and long-day photoperiod promoted maleness (Pessarakli 2016).

Other factor that can affect flowering process in cucumber is the production of ethylene, which is affected by the presence of sucrose inside the plant. High sucrose content will correlate to higher production of ethylene (Miao et al. 2010). According to Yamasaki et al (2010), the increase of ethylene in short-day plants is a result of an increase in expression of $C s A C S 2$, which then increases ethylene response through ethylene recognition by ethylene receptor CsETR1. As a result, complex CTR1 and CsETR1 cannot be formed, which cease negative regulation from CTR1, hence resulting in the increase of ethylene response (Wang et al. 2010). Ethylene signal triggers a response to the synthesis of enzyme(s) 
that lead to DNA degradation of primordial anther. Therefore, the previously hermaphrodite flower with two sex organs develops only into stigma, the female organ of flower (Wang et al. 2010). This study was performed to evaluate the effect of photoperiod on female flower production on molecular level, in order to optimize the factors in flowering mechanism that can affect the productivity of cucumber.

\section{Materials and Methods}

\section{Plant Materials}

Cucumber's seeds used in this experiment were from Mercy cultivar that represent andromonoecious. Seeds were germinated on charcoal husks for 7 days until the seedling's height was $3 \sim 5 \mathrm{~cm}$. The charcoal husks were watered daily.

Subsequently, seedlings were transferred to polybag containing soil, charcoal husks, compost, and maintained in screenhouse for acclimatization for 14 days.

\section{Photoperiod treatment}

Photoperiod used in this experiment represent the short-day ( $8 \mathrm{~h}$ irradiation), neutral-day (12 $\mathrm{h}$ irradiation), and long-day plants (16 h irradiation). Photoperiod for short-day treatment was achieved by using 2-ply 75\% shade net. Neutral and long day photoperiod were achieved by using white LEDs with Photosynthetic Active Radiation (PAR) of $100 \sim 220$ $\mu \mathrm{mol} \cdot \mathrm{m}^{-2} \cdot \mathrm{s}^{-1}$ and light intensity $600 \sim 10.000$ lux with total power input 74 watt. LEDs light was set to turned on for neutral-day and long-day photoperiod at 5.00 6.00 PM and $5.00 \sim 10.00$ PM, respectively. For control treatment, cucumbers were not given any light treatment. Plants were watered using half liter of tap water each day until 3 weeks, and then watered with a liter/day until harvest. Plants were fertilized with NPK fertilizer (16:16:16). Experiment were conducted in ITB Jatinangor screen house.

Flower quantification

Observation and quantification of flowers was conducted manually by the end of the treatments. The flowers that were counted were male and female flowers from main and lateral stems.

\section{Statistical analysis}

Data were analyzed using one way ANOVA and further by using Duncan Test at the level of $p \leq 0,05$ using SPSS Software version $22^{\text {nd }}$.

\section{In silico studies}

In silico studies in this experiment consisted of primer synthesis and modelling of signal transduction from photoperiod to female flower differentiation in cucumber. Genes used as a basis for primer synthesis were CsACS2 (Accession number: KM272632.1), CsETR1 (Accession mumber: NM_001280633.1), CsCaN (Accession number: GQ149069.1), CsPIF4 (Accession number: XM_008466464.2). Primer synthesis of CsACS2, CSETR1, CsCaN, and CsPIF4 were based on NCBI's PrimerBlast (Table 1). Primers quality were checked using oligoanalyzer software based on its Tm value, GC percentage, and predicted conformation of hairpin and dimer structure. Domain prediction was conducted with NCBI's CDD search to understand the basic function of enzymes involved in cucumber flower differentiation. Suggested model of signal transduction from phytochrome-ethylene-differentiation of female flowers was presented in Figure 2.

Table 1 Primers used in PCR reaction

\begin{tabular}{|c|c|c|}
\hline Primers & $\begin{array}{c}\text { Nucleotide sequence } \\
\left(5^{\prime}<3^{\prime}\right)\end{array}$ & $\begin{array}{c}\text { Amplicon } \\
\text { (bp) }\end{array}$ \\
\hline CsGaDPH F & TCAACGACCCCTTCATCAC & \multirow{2}{*}{236} \\
\hline CsGaDPH R & AGCAGCCTTGTCCTTGTCA & \\
\hline CsACS2 F & CTCACAAACGCAACGGTTTT & \multirow{2}{*}{167} \\
\hline CsACS2 R & CTCAAATTCATCGGCATTCCCT & \\
\hline CsETR1 F & GTTGTTGCTGTCCGTGTTCC & \multirow{2}{*}{670} \\
\hline CsETR1 R & ACCCACAACATTAAGAATAGCTTC & \\
\hline $\mathrm{CsCaN} \mathrm{F}$ & TCACGGATGCTGGTTACAGG & \multirow{2}{*}{836} \\
\hline CsCaN R & TGGTCTTAGGCGGCAAGATT & \\
\hline CsPIF4 F & TGTCTCGAATGGCTATGGGC & \multirow{2}{*}{533} \\
\hline CsPIF4 R & СТTCTACTTGGTGGAGAGCAAGG & \\
\hline
\end{tabular}




\section{PCR Analysis}

Sampling method was modified based on Yamasaki's research. Apical and lateral shoot of cucumber were excised and used for total RNA extraction with Promega SV Total RNA Isolation System (Catalog No: Z3100) based on manufacturer's instructions. Isolated RNAs were cleaned up from DNA contaminant using DNase I Thermo Scientific (Catalog No: \#EN0521). Isolated RNA was treated with with Bio-rad iScript ${ }^{\mathrm{TM}}$ cDNA Synthesis Kit (Catalog No: 170-8890) to produce First strand cDNA by previously calculating RNA concentration and RNA quality using spectrophotometer at 260, 280, 320, and $230 \mathrm{~nm}$. Synthesized cDNA was used as a template for PCR confirmation with Promega GoTaq Green Master Mix (Catalog No: M7122) and ABI Veriti ${ }^{\circledR}$ thermocycler. GaDPH was used as a control gene (Accession Number: NM_001305758.1). Procedure in PCR was modified based on manufacturer's instruction with cDNA used in the reaction was $2 \mu \mathrm{L}$. Primers used in PCR are listed in Table 1.

\section{Results and Discussion}

Total Flowers Analysis

Total male and female flowers produced from photoperiod treatments was shown in Figure 1A. This figure showed that Mercy was cucumber from andromonoecious line that produced dominant male flowers. Howevers, eight hours treatment resulted in the highest number of female flowers (14.7 flowers/plant). This treatment produced lower total male flowers compared to 12 and 16 hours photoperiod, in which eight hours treatment produced 54.7 male flowers/plant while other treatments produced around 80 male flowers/plant. Lower number of total flowers indicated that the flowering capability was correlated with photoperiod that might relate to sugar production, thus affected the total number of flowers (Taiz and Zeiger 2010; Ikram et al. 2015). These total flowers data was similar to Yamasaki's research that showed conversion between male and female flowers in the main stem that was affected by photoperiod, longer photoperiod produced higher male number and lower female number, while shorter photoperiod produced higher female number and lower male number (Yamasaki et al. 2003).

Another finding in this experiment was that the main and lateral stems produced different numbers of female flowers (Figure 1B). Eight hours irradiation produced more female flowers in the main stem, while 12 and 16 hours irradiation showed more female flowers in their lateral stem.

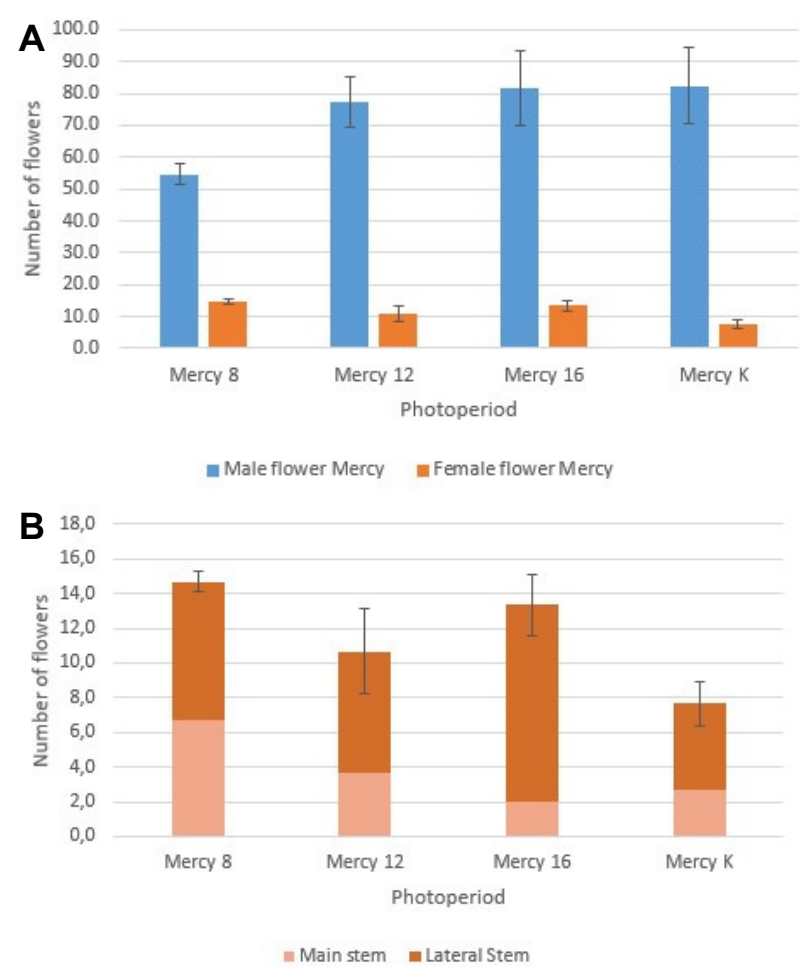

Fig. 1 (A) Total number of flowers produced by Mercy cultivar. (B) Comparison of female flowers produced by Mercy cultivar in the main stem (light orange) and lateral stem (dark orange)

The maximum number of female flowers in the main stem could be explained by the production of ethylene in apical shoot induced by shorter photoperiod. This finding was supported by Yamasaki research that showed the same effect of photoperiod (Yamasaki et al. 2003). High female flowers on cucumber main stem was also related to the increase of ethylene production that induced by shorter photoperiod (Ikram et al. 2015; Yamasaki et al. 2003). Interestingly, prolonged photoperiod to 16 hours significantly increased the female flowers in lateral stem, while the total number of female flowers in the plant was similar compared to 8 hours. Longer photoperiod increased sugar content in cucumber (Mayorazaki et al. 2015). Escalation of sugar content affected the lateral bud development (Mason et al. 2016). Apical dominance known to be affected by the role of auxin, but Mason (2014) also suggested that it may not be controlled solely by auxin, it was also controlled by the needs of sugar from shoot tip. Excised shoot tip's canceled apical dominance as a result from distributed sugar content to axillary buds (Mason et al. 2014). Therefore, higher sugar content induced by longer photoperiod influenced the development of lateral buds. Increased sugar content affected the production of lateral stem, the development of flowers, and induced ethylene production to stimulate flower differentiation to female flower (Miao et al. 2010; Ikram et 
al. 2015; Mason et al. 2014).

In spite of its difference in flower differentiation, photoperiod did not play a major role in initiation of flowering, all treatment conditions induced flowering. Therefore, cucumber could be categorized as neutral-day plant. This statement was supported by other research that showed cucumber was into neutral-day plant (Savonen 2003). It is suggested that flower production might be induced by autonomous pathway or sugar content (Taiz and Zeiger 2010; Ikram et al. 2015). In addition, Figure 1 showed that photoperiod on cucumber played a major role in sex determination. This result supported by other research such as Yamasaki (2003), Wang (2010), and Pessarakli (2016). Flower differentiation in Melon (Cucumis melo) and Watermelon (Citrullus lanatus) was also affected by photoperiod that lead to the presence of ethylene which induced the female flower determination (Girek et al. 2013; Manzano et al. 2016). However, this phenomenon was only appeared in monoecious and andromonoecious cultivar. Female-dominant cultivar (gynomonoecious) in cucumber did not shown to be affected by ethylene presence (Ikram et al. 2015).

Probability of cucumber production in Mercy cultivar depends on the capability of cucumber plant to produce female flowers (Pessarakli 2016). Even though the total number of female flowers in 8 hours and 16 hours photoperiod did not differ significantly, the energy consumption to produce each female flowers was different. 16 hours light treatment need an additional light supply in the cultivation, 8 hours photoperiod did not need any additional energy. Hence, the best photoperiod for producing female flower in cucumber

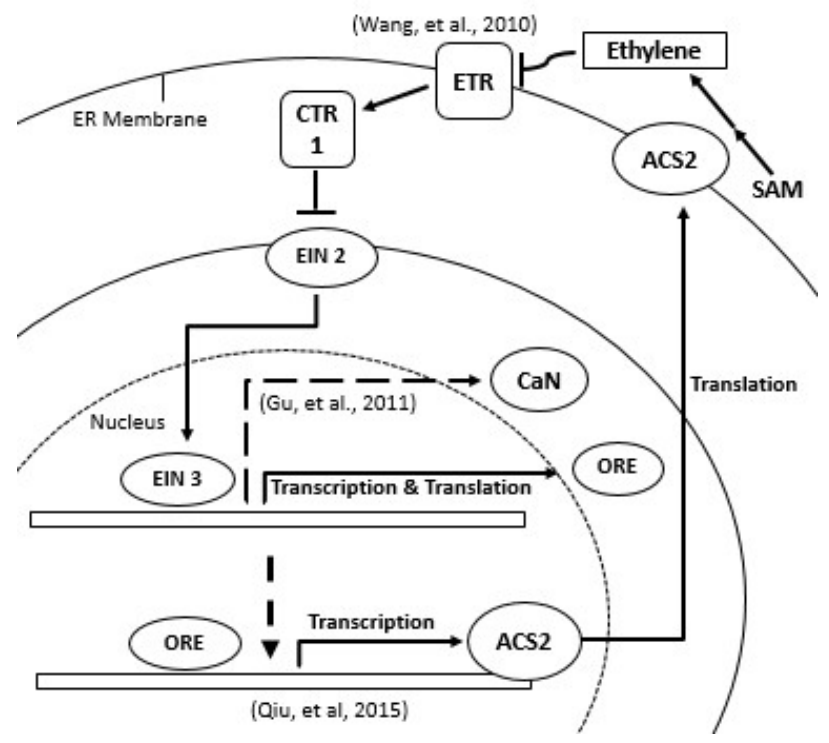

Fig. 2 Proposed model of ethylene affecting flower differentiation in cucumber
Mercy cultivar was 8 hours irradiation.

PCR Analysis and in silico studies

Result from RNA extraction was shown by electrophoregram in Figure 3A. cDNA was synthesized from the RNA and kept at $-20^{\circ} \mathrm{C}$. Gene expression analysis to confirm the model was conducted by using CsACS2, CsETR1, CsCaN, and CSPIF4 genes, started with primer synthesis from in silico study. Each gene represented the function in model signal transduction, CsACS2 for ethylene expression, CsETR1 for ethylene response, $C s C a N$ for flower differentiation, and CsPIF4 for photoperiod. Electrophoregram from PCR analysis was shown in Figure 3. Brightness in electrophoregram (Fig. 3) did not correlate to the concentration of gene expression. In silico studies showed that CsACS2 have ATT_like domain (Aspartate aminotransferase). ATT_ like function in ethylene synthesis is to transfer aspartate chain to form ACC (Marchler-Bauer et al. 2015). CsETR has HTPase_C and Histidine Kinase A domain. These domain shows that CSETR function as receptor that accepts ethylene and act as two-component system with CTR1 (Marchler-Bauer et al. 2015). CsCaN is homologous with Staphylococcal nuclease that works as nuclease for eukaryotes and CsPIF4 has Helix-Loop-Helix domain that characterized it as transcription factor (Marchler-Bauer et al. 2015).

Figure 3B showed the result of Mercy that was given 8 hours and 16 hours light treatments expressed CsACS2, CsCaN, and CsETR. These gene expression profiles showed positive correlation with total number of female flowers produced in photoperiod treatments. However, CSPIF4 was not expressed in all treatments, which might be caused by

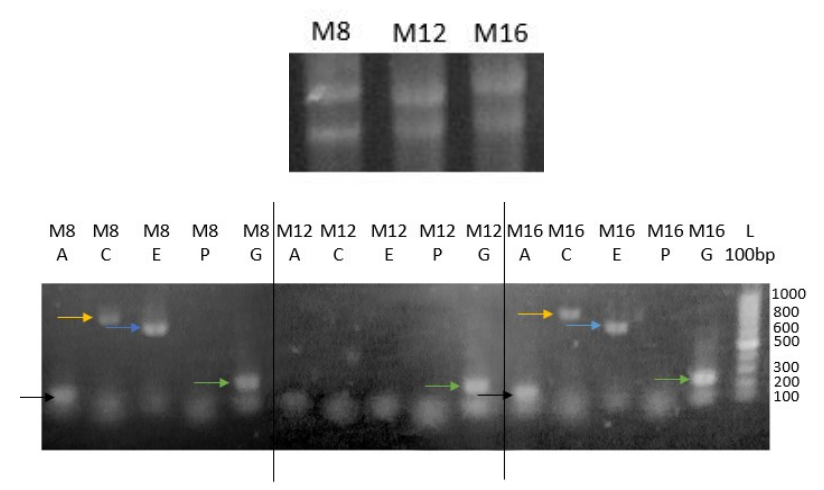

Fig. 3 (A) Electrophoregram for RNA extraction (Note : $\mathrm{M}=$ Mercy; 8,12,16 = Photoperiod). (B) Electrophoregram for gene expression analysis related to photoperiod, ethylene, and flower differentiation. (Note : $\mathrm{M}=$ Mercy; $8,12,16$ = photoperiod; $\mathrm{A}=$ ACS; $\mathrm{C}=\mathrm{CaN}$; E = ETR; P = PIF4; $\mathrm{G}=\mathrm{GaDPH}$; L = Ladder; Black arrow $=\mathrm{ACS}$ gene; Orange arrow $=\mathrm{CaN}$ gene; Blue arrow = ETR gene; Green arrow: GaDPH gene) 
inappropriate sampling time and organ, because gene is expressed at time-specific and organ-specific (Shedden and Cooper 2002). Alternatively, the primer did not match with the cDNA template, because the CsPIF4 primer was based on honeydew (Cucumis melo) (Abd-Elsalam 2003). Despite the CsACS2 expression in short day plant treatment, the expression of CsACS2 in 16 hours irradiation showed a difference to the result of Yamasaki's research (Yamasaki et al. 2003) and that explained by Miao et al. (2010) as the effect of increasing sugar produced by prolong photosynthesis that induced the ethylene, in this case CsACS2 production.

Ethylene is commonly known as plant hormone that plays important role in fruit ripening, plant growth, maturation, and signalling for self-defense mechanism (Taiz and Zeiger 2010). However, limited study has described the signal transduction pathway of ethylene in the process of sexual differentiation of flowers. Nevertheless there were studies that explained that ethylene was received by ETR receptor in hermaphrodite flowers and the response was transduced to the activation of calcium-dependent nuclease in order to stop the development of primordial anther ( $\mathrm{Gu}$ et al. 2011; Bai and Xu 2013). Therefore, alternative/additional signal transduction process that can complement the data basis on KEGG to relate phytochrome and ethylene and ethylene with flower sex determination is needed.

Based on results from this research, it was confirmed that CsACS, CsETR, dan CsCaN played a role in the female flowers differentiation. Therefore, the proposed model (Figure 2) in this research of flower differentiation could be combined with KEGG database to complement the information about the ethylene response in plants. CsCaN expression also confirmed Gu's research that $C s C a N$ played a role in flowers organ development, where cucumber's flowers, which initially were hermaphrodite, differentiated into female flowers upon the exposure of ethylene by the function of $\mathrm{CsCaN}$ as specific nuclease to primordial anther, thus arrested stamen development. This proposed model could be applied to another monoecious and andromonoecious species that showed similar effect in the presence of ethylene, such as melon and watermelon, but may not be applied to gynomonoecious cultivar, even in the same cucumber species (Girek et al. 2013; Ikram et al. 2015; Manzano et al. 2016)

Best photoperiod to achieve optimum cucumber productivity depends on its cultivar, as it based on its sex differences in flowers production. In Mercy cultivar, female flower production affected the productivity more than male flowers. The condition to achieve the highest productivity was 8 hours treatment which produced 14.7 female flowers and 54.7 male flowers. In silico study resulted on proposed model related to signal transduction model through the lightinduced CsACS2 to produce ethylene, which then followed by ethylene response through CsETR1, and finally affected CsCaN in the determination process of female flower differentiation.

This proposed model was confirmed by electrophoresis that showed bands of CsACS2, CsETR1, and CsCaN genes from plants with high number of female flowers following 8 and 16 hours treatments of photoperiod. However, expression of CsPIF4 was not found in all treatments. This PCR result confirmed that $C s A C S 2, C s E T R 1$, and CsCaN genes played a role in ethylene production and affected female flower determination. These gene expressions may be affected by photoperiod, yet still not known which genes that related photoperiod and flowering differentiation.

\section{Acknowledgement}

The researchers would like to thank Lembaga Pengelola Dana Pendidikan (LPDP) for giving research grant and PT. East West Seed Indonesia for providing cucumber's seeds used in this research.

\section{References}

Abd-Elsalam KA (2003) Bioinformatic tools and guideline for PCR primer design. African J Biot 2:91-95

Bai SN, Xu ZH (2013) Unisexual cucumber flowers, sex and sex differentiation. Int Rev Cell Mol Biol 304:1-48

Chen JC, Chiu MH, Nie RL, Cordell GA, Qiu SX (2005) Cucurbitacins and cucurbitane glycosides: structures and biological activities. Nat Pro Rep 22:386-399

Girek Z, Prodanovic S, Zdravkovic J, Zivanovic T, Ugrinovic M, Zdravkovic M (2013) The effect of growth regulators on sex expression in melon (Cucumis melo L.). Crop Breed App Biot 13:165-171

Gu HT, Wang DH, Li X, He CX, Xu ZH, Bai SN (2011) Characterization of an ethylene-inducible, calcium-dependent nuclease that is differentially expressed in cucumber flower development, New Phyto 192:590-600

Ikram MMM, Esyanti RR, Faizal A (2015) The effect of photoperiodism with led light on productivity of female flower in cucumber (Cucumis sativus L.). MATTER: Int J Sci Tech Special Issue 1:24-34

Indonesia Ministry of Agriculture (2016) Produksi Hortikultura Saat Ini. http://aplikasi.pertanian.go.id/bdsp/index.asp

Johnson H Jr. (2008) Fruit set problems in squash, melons, and cucumbers in home gardens, Cooperative Extension, Division of Agricultural Sciences, Leaflet 21242, University of 
California, pp. 1-2

Lee DH, Iwanski GB, Thoennissen NH (2010) Cucurbitacin: ancient compound shedding new light on cancer treatment. Sci World J 10:413-418

Manzano S, Aguado E, Martínez C, Megías Z, García A, Jamilena M (2016) The ethylene biosynthesis gene CitACS4 regulates monoecy/andromonoecy in watermelon (Citrullus lanatus). PLoS ONE 11:1-16

Mason MG, Ross JJ, Babst BA, Wienclaw BN, Beveridge CA (2014) Sugar demand, not auxin, is the initial regulator of apical dominance. PNAS 16:6092-6097

Mayorazaki F, Esyanti RR, Faizal A (2015) Enhancement of photosynthetic rate through photoperiod using LED in cucumber (Cucumis sativus L.). MATTER: Int J Sci Tech Special Issue 1:1-12

Miao M, Yang X, Han X, Wang K (2010) Sugar signaling is involved in the sex expression response of monoecious cucumber to low temperature. J Exp B pp. 1-8

Pessarakli M (2016) Handbook of Cucurbits : Growth, Cultural practices, and Physiology. CRC Press, New York, USA. pp. $1-237$
Reece JB, Taylor MR, Simon EJ, Dickey JL (2012) Campbell Biology : Concept \& Connection 7th Edition. Pearson, San Fransisco, USA. pp. 1-777

Savonen C (2003) What are short day and long day plants?. Oregon State University Extension Service

Scout J, Myers J (2010) Cucumber Bitterness Explained. Oregon State University Extension Service

Shedden K, Cooper S (2002) Analysis of cell-cycle-specific gene expression inhuman cells as determined by microarrays and double-thymidine block synchronization. PNAS. 99:4379-4384

Taiz L, Zeiger E (2010) Plant Physiology 5th edition. Sunderland, Sinauer. pp. 1-675

Wang DH, Li F, Duan QH, Han T, Xu ZH, Bai SN (2010) Ethylene perception is involved in female cucumber flower development. The Plant J 61:862-897

Yamasaki S, Fujii N, Takahashi H (2003) Photoperiodic regulation of CS-ACS2, CS-ACS4, and CS-ERS gene expression contributes to the femaleness of cucumber flowers through diurnal ethylene production under short-day conditions. Plant Cell Env 26:537-546 